\title{
Impact of Bethesda System of Reporting for Thyroid Cytopathology
}

\author{
${ }^{1}$ Varsha Dhume, ${ }^{2}$ Vikas Kavishwar
}

\begin{abstract}
FNAC though considered the gold standard diagnostic test in the evaluation of a thyroid nodule, has many issues regarding the terminologies and interpretation. The National Cancer Institute $(\mathrm{NCl})$ hosted the $\mathrm{NCl}$ Thyroid Fine needle Aspiration State of the Science Conference in 2007, which acknowledged the importance of developing a uniform terminology for reporting thyroid FNA results to facilitate effective communication among cytopathologists, endocrinologist, surgeons, radiologists and other healthcare providers. The $\mathrm{NCl}$ Conference concluded the terminology and morphologic criteria which formed the framework for The Bethesda system for reporting thyroid cytopathology (TBSRTC). It is a 6 tiered 'The Bethesda System for Reporting Thyroid Cytopathology' (TBSRTC) for unifying the terminology and morphologic criteria along with the corresponding risk of malignancy. Bethesda also offers management approach for all the categories. Bethesda system is presently widely accepted in western countries and is being introduced in rest of the world. This system of reporting undoubtedly represents a major step toward standardization, reproducibility and ultimately improvement in clinical significance, usefulness and predictive value of thyroid FNAC. The problems faced by the cytopathologist while implementing Bethesda during reporting are centred on AUS/FLUS category. The heterogeneity of this low-risk category leads to significant variability in its reported percentage as well as reported rate of malignancy.
\end{abstract}

Keywords: Thyroid FNAC, Bethesda, AUS, Follicular neoplasm.

How to cite this article: Dhume V, Kavishwar V. Impact of Bethesda System of Reporting for Thyroid Cytopathology. Int J Otorhinolaryngol Clin 2014;6(1):15-22.

Source of support: Nil

Conflict of interest: None

\section{BACKGROUND}

Fine needle aspiration cytology of thyroid gland plays a crucial role in diagnosis and management of thyroid lesions especially in solitary thyroid nodules. Triaging of patients with thyroid disease who are to be surgically managed has

\footnotetext{
${ }^{1}$ Associate Professor, ${ }^{2}$ Additional Professor

1,2Department of Pathology, TN Medical College and BYL Nair Hospital, Mumbai, Maharashtra, India

Corresponding Author: Varsha Dhume, Associate Professor Department of Pathology, 204/C, Badridham Society, Sant Janabai Road, Vile-Parle (East), Mumbai-40005, Maharashtra, India Phone: 9869087916, e-mail: varshadhume@hotmail.com
}

now become more refined and accurate with optimum use of thyroid FNA and better knowledge of the cytomorphological characteristics of thyroid disease.

Thyroid FNA suffers from a reporting confusion due to multiplicity of terminologies and categories, resulting into discordance between clinician and cytopathologist, thereby posing a hindrance to patient's management. To address the terminology and other issues related to thyroid FNA, The National Cancer Institute (NCI) in USA hosted the Thyroid Fine needle Aspiration State of the Science consensus Conference in 2007.

In this conference, a six tiered system for thyroid cytology terminology, with the full prose report and the appropriate code was proposed. This system called as 'The Bethesda System for Reporting Thyroid Cytopathology' (TBSRTC) worked for unifying the terminology and morphologic criteria of FNAC reporting along with the corresponding risk of malignancy. ${ }^{1}$ Each of the categories has an implied cancer risk (0-3\% for the benign category to virtually $100 \%$ for the malignant category) that links it to a rational clinical management guideline. ${ }^{2}$

In this newly adopted system, the six diagnostic categories have been designated one to six roman numbers. The categories are as follows:

i. Nondiagnostic

ii. Benign

iii. Atypia/follicular lesion of undetermined significance

iv. Follicular neoplasm/suspicious for a follicular neoplasm

v. Suspicious for malignancy

vi. Malignant.

A criteria for adequacy of a cytological preparation has been defined in Bethesda as: 'A thyroid FNA specimen is considered to be satisfactory for evaluation (and benign), at least 6 groups of benign follicular cells are required, and each group composed of atleast 10 cells.'

\section{Nondiagnostic or Unsatisfactory}

- Cyst fluid only

- Virtually acellular specimen

- Specimen obscured by blood, clotting artefact, etc.

\section{Benign}

- Consistent with a benign follicular nodule (includes adenomatous nodule, colloid nodule, etc.) 
- Consistent with lymphocytic (Hashimoto) thyroiditis

- Consistent with granulomatous (subacute) thyroiditis and other.

\section{Atypia of Undetermined Significance or Follicular Lesion of Undetermined Significance}

\section{Follicular Neoplasm or Suspicious for a Follicular Neoplasm}

Specify if Hürthle cell (oncocytic) type.

\section{Suspicious for Malignant}

- Suspicious for papillary carcinoma

- Suspicious for medullary

- Suspicious for metastasis.

\section{Malignant}

- Papillary carcinoma

- Medullary carcinoma

- Anaplastic carcinoma

- Lymphoma

- Metastatic neoplasm.

\section{Implied Risk of Malignancy and} Recommended Clinical Management ${ }^{42}$

\begin{tabular}{|l|l|l|}
\hline $\begin{array}{l}\text { Diagnostic } \\
\text { category }\end{array}$ & $\begin{array}{l}\text { Risk of } \\
\text { malignancy(\%) }\end{array}$ & Management \\
\hline $\begin{array}{l}\text { Nondiagnostic or } \\
\text { unsatisfactory }\end{array}$ & $1-4$ & $\begin{array}{l}\text { Repeat FNA with } \\
\text { ultrasound guidance }\end{array}$ \\
\hline Benign & $0-3$ & Clinical follow-up \\
\hline $\begin{array}{l}\text { Atypia of } \\
\text { undetermined } \\
\text { significance }\end{array}$ & $5-15$ & Repeat FNA \\
\hline $\begin{array}{l}\text { Follicular } \\
\text { neoplasm or } \\
\text { suspicious } \\
\text { for follicular } \\
\text { neoplasm }\end{array}$ & $15-30$ & Surgical lobectomy \\
\hline Malignant & $97-99$ & $\begin{array}{l}\text { Near total } \\
\text { thyroidectomy }\end{array}$ \\
\hline
\end{tabular}

\section{APPLICATION OF BETHESDA}

\section{Nondiagnostic for Cytological Diagnosis-Category I (Fig. 1)}

The cytopathologists have often used terms 'nondiagnostic' and 'inadequate/unsatisfactory' interchangeably. Whereas endocrinologists and surgeons have interpreted the terms differently. ${ }^{3}$ Cellularity/adequacy of thyroid FNA sample is very subjective and is dependent on the technique of the aspirator as well as on the inherent nature of the lesion (e.g. solid $v s$ cystic) adequacy includes the quality of a specimen

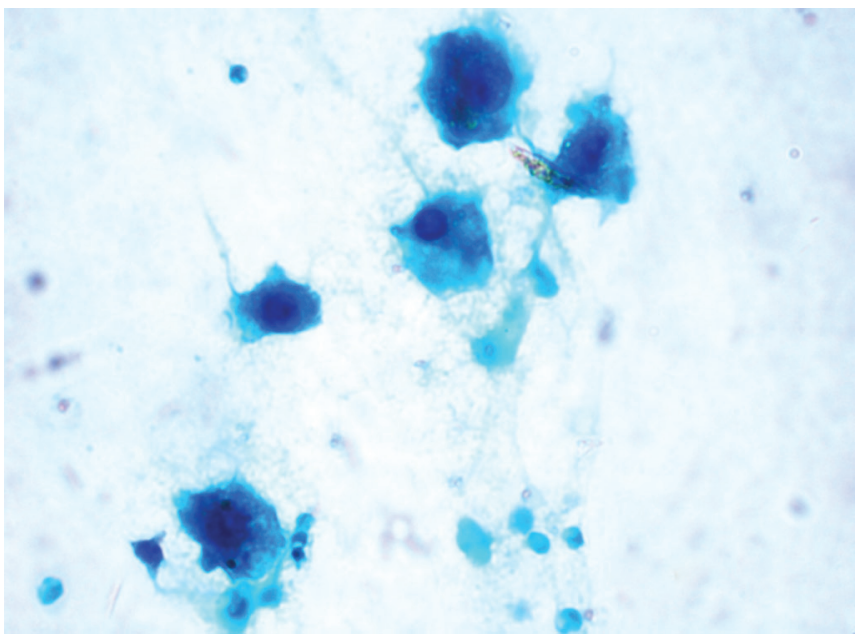

Fig. 1: Only macrophages, inadequate

which is irrefutably critical to proper interpretation. Practical application of rigid numerical criteria for cell quantity has been difficult to apply in practice. No study supports any specific numerical criteria of follicular cellularity as applicable to all cases (benign and malignant, cystic and solid) with high diagnostic accuracy. There is no consensus about a minimum number of FNA passes required to obtain adequate samples. Recommendations for adequacy generally apply only to the quantity of follicular cells and exclude consideration of macrophages, lymphocytes, and other nonmalignant cellular components. ${ }^{4,5}$ The cellularity criterion as advocated by Bethesda systems states that for adequate epithelial cellularity, samples from solid lesions should have at least six groups of thyroid follicular epithelial cells across all the submitted slides, each with at least 10 well-visualized epithelial cells.

Proficient sample collection, excellent slide preparation, processing, and staining ${ }^{6}$ are essential to ensure that observer will confidently render an accurate interpretation. Even one group of follicular cells with diagnostic features of papillary thyroid carcinoma (PTC) may constitute an adequate specimen in the proper clinical setting and should not be considered nondiagnostic despite scant cellularity. ${ }^{7}$ The presence of abundant colloid (as opposed to plasma) often indicates benign lesion despite scant follicular cells. ${ }^{8}$

The reason for a nondiagnostic sample should be clearly stated in the cytology report. Nondiagnostic samples often occur due to operation/technical problems which may result into:

- Acellular smear or smears with cellularity less than the criterion

- Smears entirely consist of blood or heavily stained with blood obscuring the epithelial cells or colloid

- Smears which are technically difficult to evaluate (e.g. poorly spread, delayed air drying or fixation artefact, prominent crush artefact, cells trapped in fibrin. 
Cystic lesions often yield with poor cellularity especially of epithelial cells.

Specimens with inadequate cellularity and yielding cyst fluid with only macrophages, usually show low-risk of malignancy if the lesion is less than $3 \mathrm{~cm}$ in size and has ultrasonographic features of a benign cystic lesion. ${ }^{4,9,10}$ It is important while auditing inadequate samples, samples from cyst fluid should be separated from those which are nondiagnostic due to different reasons listed above. In cystic thyroid lesions, there is a recognized risk of non-representative sampling, especially in cystic papillary thyroid carcinomas. One should not to report on suboptimal epithelial cellularity. Nodules with an initial ND/UNS result should be reaspirated, only after an interval of 3 months in order to prevent false positive interpretations due to reactive/reparative changes. Ultrasound guidance with immediate, on-site adequacy evaluation is preferred for such re-aspirations, especially for solid nodules. Repeat FNA have given a cytological diagnosis in about $60 \%$ of cases ${ }^{11,12}$ which turn out to be benign in most of the nodules. ${ }^{13,14}$ After two successive ND/ UNS specimens, close clinical follow-up with ultrasound or surgery should be considered, depending upon the clinical findings. In case of cystic nodules with category I diagnosis, reaspiration should be performed only if the ultrasound findings are suspicious as very low malignancy risk has been reported.

\section{Non-neoplastic Benign-Category II (Fig. 2)}

The clinical utility of FNAC in thyroid has been its ability to diagnose benign lesion reliably and thus sparing many patients with nodular thyroid disease unnecessary surgery. A benign result is the most common FNA interpretation (approx. $65 \%$ of all cases). ${ }^{15,16}$ Benign results are further subclassified as benign follicular nodules, thyroiditis, or other less common entities. ${ }^{17,18}$ The benign follicular nodule (BFN) encompasses a group of benign lesions with similar cytologic features that are classified histologically as nodules in nodular goiter (NG), hyperplastic (adenomatoid) nodules, colloid nodules, nodules in Graves' disease, and a subset of follicular adenomas (those of macrofollicular type). The distinction among these different histologic entities may not possible on cytology. However, it is less significant in practice as these lesions are all benign and, therefore, are usually managed in a similar, conservative manner. The designation 'benign follicular nodule' applies to a cytologic sample that is adequate for evaluation and consists predominantly of colloid and benign-appearing follicular cells in varying proportions, Hürthle cells and macrophages. Depending on clinical presentation, a more specific term like colloid nodule, nodular goiter, hyperplastic or adenomatous nodule and Graves' disease may be used. ${ }^{19}$

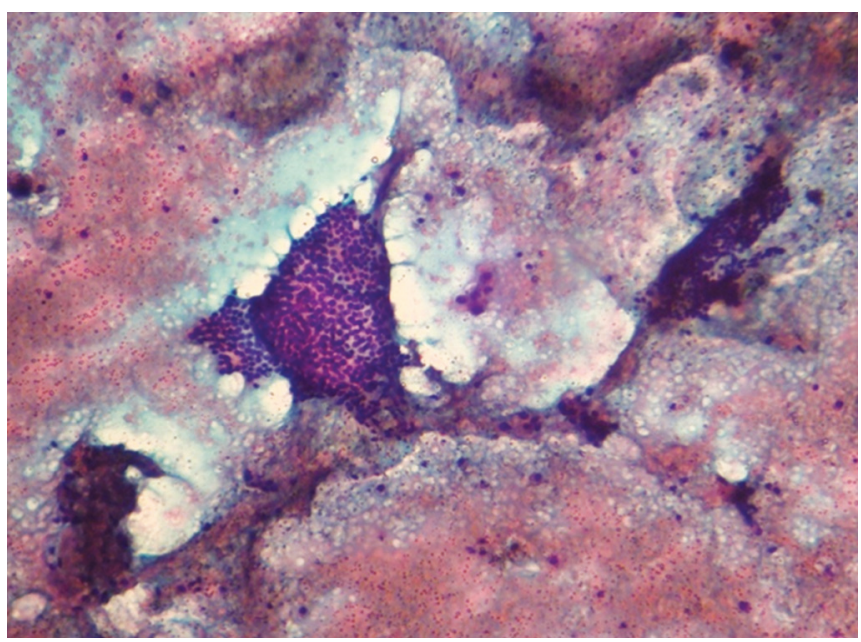

Fig. 2: Adenomatous goiter

Benign cytopathology is associated with a very low-risk of malignancy, almost less than $1 \% .^{20,21}$ Aspirates from malignant lesions like FVPC, papillary carcinoma with cystic changes, Hürthle cell neoplasm in the background of thyroiditis may mimic goiter and may lead to false negative FNA results. Patients with a benign nodule are followed by clinical and periodic ultrasound examinations and patients may undergo repeat FNAC if nodule increases in size.

\section{Atypia of Undetermined Significance- Category III (Fig. 3)}

This category was also labelled as the category of follicular cells of undetermined significance in the classification system proposed by the NCI thyroid FNA state of the science conference. This category was reserved for aspirates with findings intermediate between benign and malignant process and often characterized by borderline cellularity. The diagnostic category 'Atypia of undetermined significance' (AUS) is reserved for specimens that contain cells (follicular, lymphoid or other) with architectural and/or nuclear atypia that is not sufficient to be classified as suspicious for a follicular neoplasm, suspicious for malignancy or malignant.

1. There is a prominent population of microfollicles which falls short for the diagnosis of 'Follicular neoplasm/ suspicious for follicular neoplasm.'

2. There is a predominance of Hürthle cells in a sparsely cellular aspirate with scant colloid.

3. Interpretation of follicular cell atypia (nuclear enlargement, pale and smudgy chromatin, mildly irregular nuclear contour) is hindered by sample preparation artefacts like air-drying artefact or clotting artefact with apparent cellular crowding.

4. A moderately or markedly cellular sample is composed exclusively of Hürthle cells, yet the clinical setting suggestive of benign lesions like lymphocytic (Hashimoto) thyroiditis or multinodular goiter (MNG). 


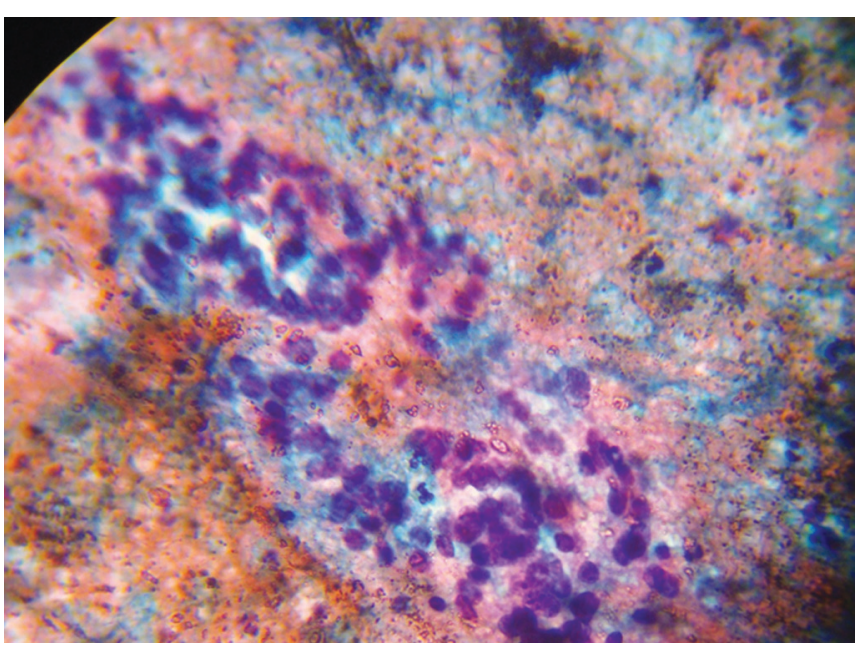

Fig. 3: Atypia of unknown significance

5. Focal features suggestive of papillary carcinoma in an otherwise predominantly benign-appearing sample, even in the presence of cystic lesion.

6. A minor population of follicular cells with nuclear atypia in following settings:

a. Specimens from patients with a history of radioactive iodine, carbimazole or other pharmaceutical agents.

b. Repair due to involutional changes such as cystic degeneration and or hemorrhage.

7. Atypical lymphoid infiltrate insufficient for the general category 'suspicious for malignancy.'

8. Not otherwise categorized. ${ }^{24}$

Frequency of AUS diagnosis in thyroid FNA has been reported to be 3 to $18 \% .{ }^{22-24,42}$ Bethesda recommends frequency of AUS should be less than $7 \%$ of all thyroid FNA interpretations. This figure may be further refined as more laboratories report their experiences of using the AUS designation. AUS is a category of last resort and should not be used indiscriminately. ${ }^{31}$

Separation of the AUS category from suspicious for malignancy is more problematic in aspirates with focal features of papillary carcinoma. A pattern diagnosed by some cytologists as atypical nuclear features with a qualifier that papillary carcinoma cannot be ruled out is associated with papillary carcinoma in approximately 30 to $40 \%$ of cases. ${ }^{25,26}$ A second pattern highly associated with the follicular variant of papillary carcinoma is characterized by diffuse but subtle nuclear enlargement, nuclear irregularity, and only occasional intranuclear grooves, sometimes associated with a microfollicular architecture. ${ }^{27}$

The recommended management for an initial AUS interpretation is the clinical correlation and a repeat FNA at an appropriate interval of 3 to 6 months. ${ }^{28} \mathrm{~A}$ repeat FNA usually results in a more definitive interpretation; only about 20 to $25 \%$ of nodules are repeatedly AUS. The risk of malignancy for an AUS nodule is difficult to ascertain because only a subset of cases in this category have surgical follow-up. In cases with two consecutive diagnosis of AUS, surgical management with use of frozen section can be considered. More refinement of AUS category can be achieved after extensive application of Bethesda with appropriate follow-up.

\section{Follicular Neoplasm—Category IV (Fig. 4)}

In the Bethesda system, the terms 'Follicular neoplasm' and 'Suspicious for follicular neoplasm' are equally acceptable for this category. 'Suspicious for a follicular neoplasm (SFN)' is preferred by some laboratories because a significant proportion (up to $35 \%$ ) of cases prove not to be neoplasms but rather hyperplastic proliferations in NG. ${ }^{29-31}$

This diagnostic category refers to a cellular aspirate comprised of follicular cells, arranged in microfollicles with significant nuclear crowding. Cases that demonstrate the nuclear features of papillary carcinoma are excluded from this category.

The hallmark of the FN/SFN specimen is the presence of a significant architectural alteration in the majority the follicular cells in the form of crowded and overlapping follicular cells. To improve reproducibility, it has been proposed that the 'microfollicles' designation must be limited to crowded, flat groups of less than 15 follicular cells arranged in a circle that is at least two-thirds complete. ${ }^{32}$ Although most FN/SFNs are highly cellular specimens, cellularity by itself is not sufficient to merit this designation. ${ }^{33}$ If there is dominant macrofollicle pattern without overlap or crowding the lesion can be considered benign. Similarly, nuclear atypia by itself is not diagnostic of malignancy or even neoplasia, as hyperplastic nodules and follicular adenomas can demonstrate nuclear enlargement and hyperchromasia. ${ }^{34,35}$ The risk of malignancy in this category has been found in the range of 15 to $30 \%$, the common malignant lesions falling in this category are follicular variant of papillary carcinoma and follicular carcinoma. The recommended management for the diagnosis of FN/SFN is surgical excision of the lesion, most often a hemithyroidectomy or lobectomy. ${ }^{28,36}$ The interpretation 'Follicular neoplasm, Hürthle cell type' or 'Suspicious for a follicular neoplasm, Hürthle cell type' refers to a cellular aspirate that consists exclusively (or almost exclusively) of Hürthle cells. Oncocytic cells with nuclear features of papillary carcinoma are excluded from this category. The sample consists almost exclusively of Hürthle cells showing abundant granular cytoplasm, enlarged, central or eccentrically located, round nuclei, prominent nucleoli with small cell dysplasia or large cell dysplasia If Hürthle cells are accompanied by abundant colloid, the 


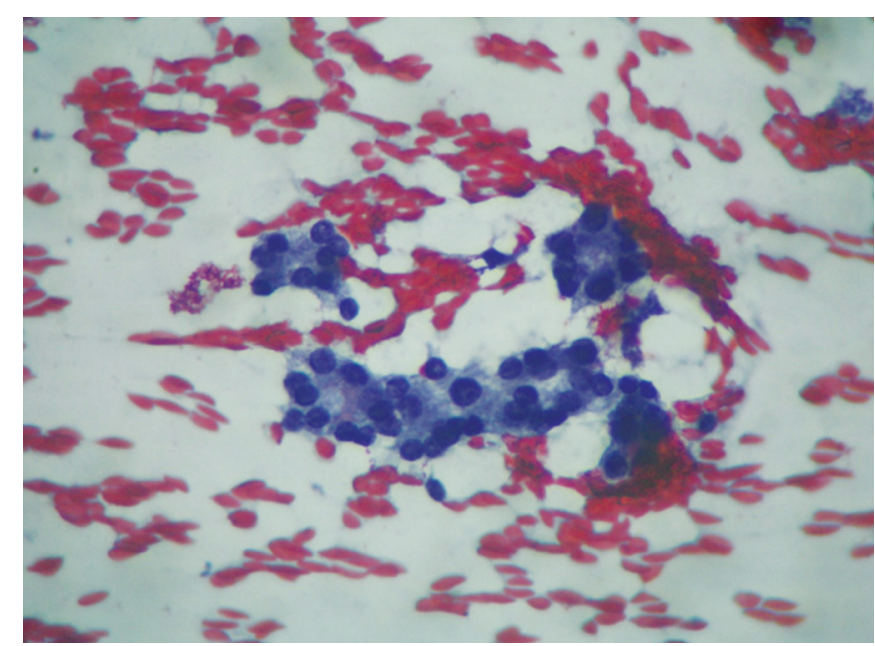

Fig. 4: Suspicious of follicular neoplasm

sample is interpreted to be benign. Two groups of investigators have recently shown that Hürthle cell aspirates that have neither small-cell nor large-cell dysplasia are almost never malignant. ${ }^{37,38}$ Many of these borderline lesions can be accurately diagnosed at the time of frozen section based on architectural features. Thus, patients with this diagnosis are candidates for lobectomy with frozen section and possible completion thyroidectomy at a single surgical procedure.

\section{Suspicious of Malignancy- Category V (Fig. 5)}

A category that conveys a strong suspicion for malignancy, but does not allow a confidant malignant diagnosis therefore, called as 'Suspicious for malignancy (SFM). ${ }^{39}$ This will include specimens of low cellularity and mixed cell types (normal and atypical). The tumor type suspected should be clearly stated, and will often be papillary carcinoma.

\section{SUSPICIOUS OF PAPILLARY CARCINOMA}

\section{Patchy Nuclear Changes Pattern (Pattern A)}

The sample is moderately cellular. Benign follicular cells (arranged predominantly in macrofollicle fragments) are admixed with cells that have nuclear enlargement, nuclear pallor, nuclear grooves, nuclear membrane irregularity, and/ or nuclear molding. Intranuclear pseudoinclusions (INCIs) are rare or absent.

\section{Incomplete Nuclear Changes Pattern (Pattern B)}

The sample is sparsely, moderately, or highly cellular with generalized mild-to-moderate nuclear enlargement, nuclear pallor, nuclear grooves. Nuclear membrane irregularity, nuclear molding, intranuclear pseudoinclusions are focal or absent.

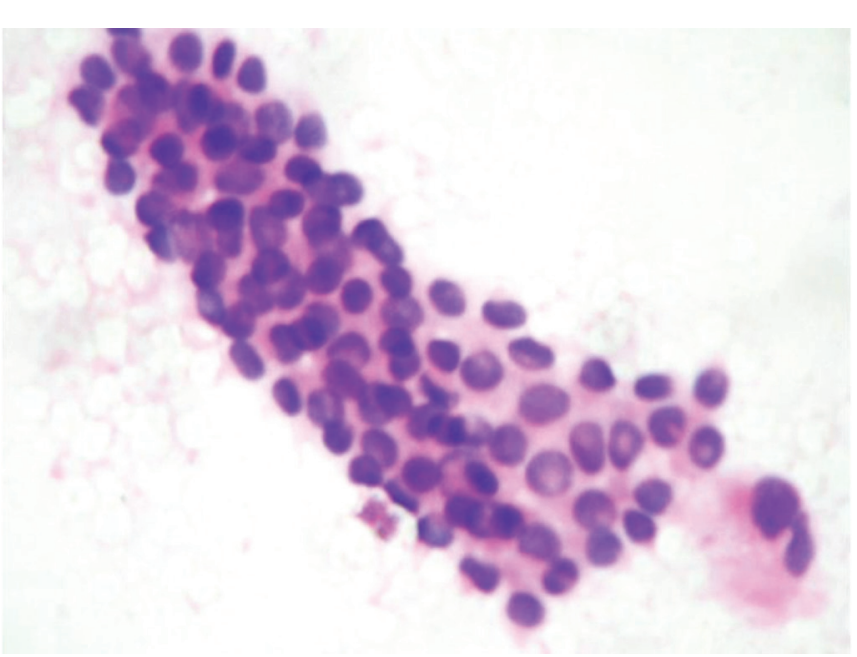

Fig. 5: Suspicious of malignancy

\section{Sparsely Cellular Specimen Pattern (Pattern C)}

Very sparsely cellular sample with diagnostic features of PTC.

\section{Cystic Degeneration Pattern (Pattern D)}

There is evidence of cystic degeneration based on the presence of hemosiderin laden macrophages. Follicular cells show enlarged, pale nuclei, focal nuclear grooves, but INCIs are rare or absent. Occasionally, large, atypical, 'histiocytoid' cells and rare calcifications resembling psammomatous bodies may be seen.

\section{SUSPICIOUS FOR MEDULLARY CARCINOMA}

Sparsely or moderately cellular sample with a monomorphic population of noncohesive small or medium sized cells with a high nuclear/cytoplasmic (N/C) ratio. A lymphoid lesion or medullary carcinoma may be considered. Nuclei are eccentrically located, with smudged chromatin and there is lack of discernible cytoplasmic granules. Small fragments of amorphous material can be debated between colloid $v s$ amyloid.

\section{SUSPICIOUS FOR LYMPHOMA}

The cellular sample with numerous monomorphic small- to intermediate sized lymphoid cells or sparsely cellular sample with atypical lymphoid cells.

\section{MANAGEMENT}

This category indicates surgery as expected risk of malignancy is in the range of 60 to $77 \%$. The contribution of intraoperative frozen section and/or touch imprint after a 'suspicious' FNA diagnosis is unclear. On comparison with frozen section, FNA has been consistently shown to have at least a comparable, if not higher, sensitivity and PPV for PTC. ${ }^{40,41}$ 


\section{Malignant-Category VI (Fig. 6)}

These samples are those that can be confidently diagnosed as malignant. The tumor type should be clearly stated, e.g. papillary thyroid carcinoma or anaplastic thyroid carcinoma or lymphoma. A malignant thyroid FNA diagnosis accounts for 4 to $8 \%$ of all thyroid FNAs. ${ }^{42}$ Papillary thyroid carcinoma is the most common malignant neoplasm accounting for $80 \%$ of the cases.

\section{Criteria (for All Types of PTC, Conventional and Variants)}

Follicular cells are arranged in papillae and/or syncytiallike monolayers.

Swirling sheets ('onion-skin' or 'cartwheel' patterns) are sometimes seen. Papillary architecture though commonly seen but is not required for the diagnosis.

The characteristic nuclear features include enlarged pale, oval or irregularly shaped, sometimes molded nuclei, longitudinal nuclear grooves, intranuclear cytoplasmic pseudoinclusions (INCI), powdery chromatin (Orphan Annie nuclei), marginally placed micronucleoli. Solitary or multiple Psammoma bodies are sometimes present.

Multinucleated giant cells are common but Hürthle cell metaplasia or squamous metaplasia are seen occasionally. The amount of colloid is variable and may be stringy, ropy, or 'bubble-gum'- like.

\section{FOLLICULAR VARIANT OF PAPILLARY CARCINOMA}

The follicular variant of PTC (FVPTC) is a PTC in which the tumor is completely or almost completely composed of small to medium-sized follicles lined by cells with the nuclear features of a PTC. Samples are usually hypercellular, with syncytial-like fragments containing microfollicles

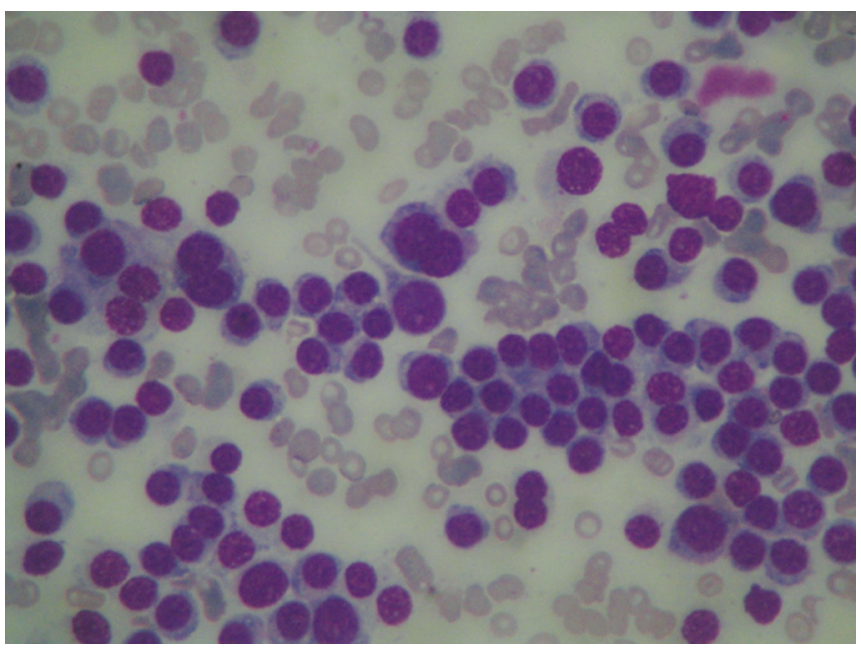

Fig. 6: Medullary carcinoma ('rosettes'). Dispersed microfollicular clusters, isolated neoplastic follicles, and some sheets with branched irregular contours may also be present. Colloid may be typically dense-staining, thick and sometimes within neoplastic follicles.

In contrast to conventional PTC, the typical cytological features are absent or inconspicuous and nuclear changes are often subtle. FVPTC typically show cells with nuclear enlargement and chromatin clearing, but nuclear grooves and INCIs are less common than in conventional PTC and many FVPTCs are interpreted as 'suspicious for papillary carcinoma' rather than unequivocally malignant. ${ }^{43,44}$ Most of these patients undergo near total or total thyroidectomy as predicted risk of malignancy is 97 to $99 \%$.

\section{SIGNIFICANCE OF BETHESDA SYSTEM}

The Bethesda system thus allows standardization in reporting, improves perceptions of diagnostic terminology between cytopathologists and clinicians, and leads to more consistent management approaches. ${ }^{45}$ Bethesda System for reporting thyroid fine-needle aspiration (FNA) specimens undoubtedly represents a major step toward standardization, reproducibility, and ultimately to improve $e^{46}$ clinical significance, usefulness, and predictive value of thyroid FNA. ${ }^{48}$ It helps to communicate thyroid fine needle aspiration interpretations to referring physicians in terms that are succinct, unambiguous and clinically helpful and it will be source of information for pathologists as well. ${ }^{10}$

\section{PROBLEMS WITH BETHESDA}

Though Bethesda has reduced the confusion in cytopathology reporting and differences in perceptions of diagnosis between cytopathologists and clinicians, it has its grey zones. These grey zones include 'borderline' lesions characterized by aspirates with atypia of undetermined significance and/or with a microfollicular pattern. Hence, it is interesting to compare the 6 categories in Bethesda with the 5 classes proposed by the British Association-Royal College of Physicians in $2002^{47,48}$ and modified by the Italian Society of Pathology and Cytopathology-Italian Section of the International Academy of Pathology in 2007. ${ }^{49}$ All classification systems provided category for Nondiagnostic FNA samples, a category for benign lesions, and a category for malignant lesions. However, notable differences is the single category for all borderline lesions, namely follicular lesion and follicular proliferation, provided by British and the Italian reporting systems respectively. The Bethesda introduces 2 categories for borderline lesions: 'atypia /follicular lesion of undetermined significance' and 'follicular neoplasm or suspicious for a follicular neoplasm.' 
In Bethesda system (TBSRTC) morphologic criteria have been defined for each category with corresponding risk of malignancy. Yet, this system faces some difficulties in category III of AUS.

The most controversial category within TBS is 'atypia of undetermined significance/follicular lesion of undetermined significance' AUS. The heterogeneity of this low-risk category inevitably means that there will be differences in its utilization with significant variability in AUS rates noted among individual practitioners as well as between laboratories. ${ }^{50-61}$ Higher risk of malignancy has been reported in recent literature for category III and IV. In our experience, it could be attributed to adequacy related issues like clotting and drying artefacts, sampling errors which may miss papillary microcarcinoma, follicular patterned lesions which have interpretation issues. The selection bias for cases which were selected for surgical management also contribute the higher malignancy risk.

\section{FUTURE TRENDS}

The Bethesda thyroid conference has explored the potential of ancillary tests, immunomarkers and molecular tools applied on FNA samples to identify thyroid cancers. Molecular testing using markers such as BRAF, RET/PTC, RAS and paired box gene (PAX) peroxisome proliferatoractivated receptor-c (PPAR-c) shows more promise for wider applicability in thyroid cytodiagnosis.

\section{REFERENCES}

1. Mufti ST, Molah R. The Bethesda system for reporting thyroid cytopathology: a five-year retrospective review of one center experience. Int J Health Sci, Qassim Univ 6(2).

2. Bongiovanni M, Cibas E, Faquin WC. The role of Thyroid fine needle aspiration cytology and the Bethesda system for reporting thyroid cytopathology. Diagnostic Histopathology 2011;17:95-105.

3. Oertel YC. Unsatisfactory (vs. nondiagnostic) thyroidal aspirates: a semantic issue? Diagn Cytopathol 2006;34(2):87-88.

4. Pitman MB, Abele J, Ali SZ, et al. Techniques for thyroid FNA: a synopsis of the National Cancer Institute Thyroid Fine-Needle Aspiration State of the Science Conference. Diagn Cytopathol 2008;36(6):407-424.

5. Jing $\mathrm{X}$, Michael $\mathrm{CW}, \mathrm{Pu} \mathrm{RT}$. The clinical and diagnostic impact of using standard criteria of adequacy assessment and diagnostic terminology on thyroid nodule fine needle aspiration. Diagn Cytopathol 2008;36(3):161-166.

6. Renshaw AA. Evidence-based criteria for adequacy in thyroid fine-needle aspiration. Am J Clin Pathol 2002;118(4):518-521.

7. Deshpande V, Kapila K, Sai KS, Verma K. Follicular neoplasms of the thyroid. Decision tree approach using morphologic and morphometric parameters. Acta Cytol 1997;41(2):369-376.

8. Pitman MB, Abele J, Ali SZ, et al. Techniques for thyroid FNA: a synopsis of the National Cancer Institute Thyroid Fine-Needle Aspiration State of the Science Conference. Diagn Cytopathol 2008;36(6):407-424.
9. Choi KU, Kim JY, Park DY, et al. Recommendations for the management of cystic thyroid nodules. ANZ J Surg 2005;75(7):537-541.

10. Nguyen GK, Ginsberg J, Crockford PM. Fine-needle aspiration biopsy cytology of the thyroid. Its value and limitations in the diagnosis and management of solitary thyroid nodules. Pathol Annu 1991;26(Pt 1):63-91.

11. Orija IB, Pineyro M, Biscotti C, Reddy SS, Hamrahian $\mathrm{AH}$. Value of repeating a nondiagnostic thyroid fine-needle aspiration biopsy. Endocr Pract 2007;13(7):735-742.

12. Alexander EK, Heering JP, Benson CB, et al. Assessment of nondiagnostic ultrasoundguided fine needle aspirations of thyroid nodules. J Clin Endocrinol Metab 2002;87(11):4924-4927.

13. MacDonald L, Yazdi HM. Nondiagnostic fine needle aspiration biopsy of the thyroid gland: a diagnostic dilemma. Acta Cytol 1996;40(3):423-428.

14. Tamez-Perez HE, Gutierrez-Hermosillo H, Forsbach-SanchezG, et al. Nondiagnostic thyroid fine needle aspiration cytology: outcome in surgical treatment. Rev Invest Clin 2007;59(3):180-183.

15. Gharib H, Goellner JR, Johnson DA. Fine-needle aspiration cytology of the thyroid: a 12-year experience with 11, 000 biopsies. Clin Lab Med 1993;13:699-709.

16. Gharib H, Goellner JR. Fine-needle aspiration biopsy of the thyroid: an appraisal. Ann Int Med 1993;118:282-289.

17. Baloch ZW, Cibas ES, Clark DP, et al. The National Cancer Institute Thyroid fine needle aspiration state of the science conference: a summation. Cyto J 2008;5(6).

18. Baloch ZW, LiVolsi VA, Asa SL, et al. Diagnostic terminology and morphologic criteria for cytologic diagnosis of thyroid lesions: a synopsis of the National Cancer Institute Thyroid Fine-Needle Aspiration State of the Science Conference. Diagn Cytopathol 2008;36(6):425-437.

19. Yassa L, Cibas ES, Benson CB, et al. Long-term assessment of a multidisciplinary approach to thyroid nodule diagnostic evaluation. Cancer 2007;111(6):508-516.

20. Grant CS, Hay ID, Gough IR, McCarthy PM, Goellner JR. Long-term follow-up of patients with benign thyroid fine needle aspiration cytologic diagnoses. Surgery 1989;106:980-985.

21. Yang J, Schnadig V, Logrono R, Wasserman PG. Fine-needle aspiration of thyroid nodules: a study of 4703 patients with histologic and clinical correlations. Cancer 2007;111(5):306-315.

22. Renshaw AA. Accuracy of thyroid fine-needle aspiration using receiver operator characteristic curves. Am J Clin Pathol 2001;116:477-482.

23. Renshaw AA. Focal features of papillary carcinoma of the thyroid in fine-needle aspiration material are strongly associated with papillary carcinoma at resection. Am J Clin Pathol 2002;118(2):208-210.

24. Weber D, Brainard J, Chen L. Atypical epithelial cells, cannot exclude papillary carcinoma, in fine needle aspiration of the thyroid. Acta Cytol 2008;52(3):320-324.

25. Logani S, Gupta PK, LiVolsi VA, et al. Thyroid nodules with FNA cytology suspicious for follicular variant of papillary thyroid carcinoma: follow-up and management. Diagn Cytopathol 2000;23(6):380-385.

26. Layfield LJ, Abrams J, Cochand-Priollet B, et al. Post-thyroid FNA testing and treatment options: a synopsis of the National Cancer Institute Thyroid Fine Needle Aspiration State of the Science Conference. Diagn Cytopathol 2008;36(6):442-448.

27. Baloch ZW, Fleisher S, LiVolsi VA, Gupta PK. Diagnosis of "follicular neoplasm": a gray zone in thyroid fine-needle aspiration cytology. Diagn Cytopathol 2002;26(1):41-44. 
28. Yang J, Schnadig V, Logrono R, Wasserman PG. Fine-needle aspiration of thyroid nodules: a study of 4703 patients with histologic and clinical correlations. Cancer 2007;111(5):306-315.

29. Schlinkert RT, van Heerden JA, Goellner JR, et al. Factors that predict malignant thyroid lesions when fine-needle aspiration is 'suspicious for follicular neoplasm'. Mayo Clin Proc 1997;72(10):913-916.

30. Kelman AS, Rathan A, Leibowitz J, Burstein DE, Haber RS. Thyroid cytology and the risk of malignancy in thyroid nodules: importance of nuclear atypia in indeterminate specimens. Thyroid 2001;11(3):271-277.

31. Renshaw AA, Wang E, Wilbur D, Hughes JH, Haja J, Henry MR. Interobserver agreement on microfollicles in thyroid fine-needle aspirates. Arch Pathol Lab Med 2006;130(2):148-152.

32. Suen KC. How does one separate cellular follicular lesions of the thyroid by fine-needle aspiration biopsy? Diagn Cytopathol 1988;4:78-81.

33. Stelow EB, Bardales RH, Crary GS, et al. Interobserver variability in thyroid fine-needle aspiration interpretation of lesions showing predominantly colloid and follicular groups. Am J Clin Pathol 2005;124(2):239-244.

34. Goldstein RE, Netterville JL, Burkey B, Johnson JE. Implications of follicular neoplasms, atypia and lesions suspicious for malignancy diagnosed by fine-needle aspiration of thyroid nodules. Ann Surg 2002;235(5):656-662.

35. Gharib H, Papini E, Valcavi R. et al. American Association of Clinical Endocrinologists and Associazione Medici Endocrinologi medical guidelines for clinical practice for the diagnosis and management of thyroid nodules. Endocr Pract 2006;12(1):63-102.

36. Renshaw AA. Hurthle cell carcinoma is a better gold standard than Hurthle cell neoplasm for fine-needle aspiration of the thyroid: defining more consistent and specific cytologic criteria. Cancer 2002;96(5):261-266.

37. Wu HH, Clouse J, Ren R. Fine-needle aspiration cytology of Hurthle cell carcinoma of the thyroid. Diagn Cytopathol 2008;36(3):149-154.

38. Wang HH. Reporting thyroid fine-needle aspiration: Literature review and a proposal. Diagn Cytopathol 2006;34(1):67-76.

39. Hamburger JI, Husain M. Contribution of intraoperative pathology evaluation to surgical management of thyroid nodules. Endocrinol Metab Clin North Am 1990;19(3):509-522.

40. Lee TI, Yang HJ, Lin SY, et al. The accuracy of fine-needle aspiration biopsy and frozen section in patients with thyroid cancer. Thyroid 2002;12(7):619-626.

41. Gharib H, Goellner JR, Johnson DA. Fine-needle aspiration cytology of the thyroid: a 12-year experience with 11,000 biopsies. Clin Lab Med 1993;13:699-709.

42. Mesonero CE, Jugle JE, Wilbur DC, Nayar R. Fine-needle aspiration of the macrofollicular and microfollicular subtypes of the follicular variant of papillary carcinoma of the thyroid. Cancer 1998;84(4):235-244.

43. Baloch ZW, Gupta PK, Yu GH, Sack MJ, LiVolsi VA. Follicular variant of papillary carcinoma. Cytologic and histologic correlation. Am J Clin Pathol 1999;111(2):216-222.

44. Mondal SK, Sinha S, Basak B, Roy DN, Sinha SK. The Bethesda system for reporting thyroid fine needle aspirates: a cytologic study with histologic follow-up. J Cytol 2013 Apr-Jun; 30(2):94-99.

45. Cibas ES, Ali SZ. The Bethesda System for Reporting Thyroid Cytopathology. Am J Clin Pathol 2009;132:658-665.

46. Layfield LJ, Morton MJ, Cramer HM, et al. Implications of the proposed thyroid fine-needle aspiration category of 'follicular lesion of undetermined significance': a 5-year multiinstitutional analysis. Diagn Cytopathol 2009;37:710-714.

47. Downs-Kelly E, Mendelin JE, Bennett AE, et al. Poor interobserver agreement in the distinction of high-grade dysplasia and adenocarcinoma in pretreatment Barrett's esophagus biopsies. Am J Gastroenterol 2008;103:2333-2341.

48. Baloch ZW, LiVolsi VA, Asa SL, et al. Diagnostic terminology and morphologic criteria for cytologic diagnosis of thyroid lesions: a synopsis of the National Cancer Institute Thyroid Fine-Needle Aspiration State of the Science Conference. Diagn Cytopathol 2008;36:425-437.

49. Abele JS, Levine RA. Diagnostic criteria and risk-adapted approach to indeterminate thyroid cytodiagnosis. Cancer (Cancer Cytopathol) 2010;118:415-422.

50. Faquin WC, Baloch ZW. Fine-needle aspiration of follicular patterned lesions of the thyroid: diagnosis, management, and follow-up according to National Cancer Institute (NCI) recommendations. Diagn Cytopathol 2010;38:731-739.

51. Jing X, Roh MH, Knoepp SM, Zhao L, Michael CW. Minimizing the diagnosis of 'follicular lesion of undetermined significance' and identifying predictive features for neoplasia.Diagn Cytopathol (published online ahead of print October 14, 2010).

52. Jo VY, Stelow EB, Dustin SM, Hanley KZ. Malignancy risk for fine-needle aspiration of thyroid lesions according to the Bethesda System for Reporting Thyroid Cytopathology. Am J Clin Pathol 2010;134:450-456.

53. Kim SK, Hwang TS, Yoo YB, et al. Surgical results of thyroid nodules according to a management guideline based on the BRAF(V600E) mutation status. J Clin Endocrinol Metab 2011;96:658-664.

54. Layfield LJ, Morton MJ, Cramer HM, Hirschowitz S. Implications of the proposed thyroid fine-needle aspiration category of 'follicular lesion of undetermined significance': a 5-year multi-institutional analysis. Diagn Cytopathol 2009;37:710-714.

55. Marchevsky AM, Walts AE, Bose S, et al. Evidence-based evaluation of the risks of malignancy predicted by thyroid fine needle aspiration biopsies. Diagn Cytopathol 2010;38:252-259.

56. Nayar R, Ivanovic M. The indeterminate thyroid fine-needle aspiration: experience from an academic center using terminology similar to that proposed in the 2007 National Cancer Institute Thyroid Fine Needle Aspiration State of the Science Conference. Cancer (Cancer Cytopathol) 2009;117:195-202.

57. Ohori NP, Nikiforova MN, Schoedel KE, et al. Contribution of molecular testing to thyroid fine-needle aspiration cytology of 'follicular lesion of undetermined significance/atypia of undetermined significance.' Cancer (Cancer Cytopathol) 2010;118:17-23.

58. Rabaglia JL, Kabbani W, Wallace L, et al. Effect of the Bethesda system for reporting thyroid cytopathology on thyroidectomy rates and malignancy risk in cytologically indeterminate lesions. Surgery 2010;148:1267-1272.

59. Renshaw AA. Should 'atypical follicular cells' in thyroid fineneedle aspirates be subclassified? Cancer (Cancer Cytopathol) 2010;118:186-189.

60. Theoharis CG, Schofield KM, Hammers L, Udelsman R, Chhieng DC. The Bethesda thyroid fine-needle aspiration classification system: year 1 at an academic institution. Thyroid 2009;19:1215-1223.

61. VanderLaan PA, Marqusee E, Krane JF. Clinical outcome for atypia of undetermined significance in thyroid fine-needle aspirations: should repeated FNA be the preferred initial approach? Am J Clin Pathol 2011;135:770-775. 